\title{
Brief screening items to identify spanish-speaking adults with limited health literacy and numeracy skills
}

\author{
Rashmi Singh ${ }^{1}$, Laura Scott Coyne ${ }^{2}$ and Lorraine S. Wallace ${ }^{3 *}$
}

\begin{abstract}
Background: Limited health literacy $(\mathrm{HL})$ and numeracy have been shown to be associated with a wide array of poor health-related outcomes, knowledge, and behaviors. The purpose of this study was to evaluate the clinical utility of brief HL and numeracy screening items in identifying Spanish-speaking adults' HL and numeracy skills.

Methods: We studied convenience samples of native Spanish-speaking adults in Columbus, Ohio. A trained research assistant administered sociodemographic items, $\mathrm{HL}$ and numeracy screening items, Short Assessment of Health Literacy (SAHL), and Newest Vital Sign (NVS) to participants in Spanish.

Results: Participants $(n=151)$ averaged $36.8 \pm 11.0$ years of age and $54.7 \%$ were female. Average SAHL score was $15.7 \pm 2.8$ (range $=4$ to 18 ), while the average NVS score was $1.7 \pm 1.5$ (range $=0$ to 6). "How confident are you filling out medical forms by yourself?" performed best in detecting limited NVS scores (AUROC $=0.66 ; 95 \%$ confidence interval $[\mathrm{Cl}]=0.57-0.75$ ), limited/marginal NVS scores (AUROC $=0.75 ; 95 \% \mathrm{Cl}=0.65-0.84$ ), and inadequate SAHL scores (AUROC $=0.69 ; 95 \% \mathrm{Cl}=0.58-0.79$ ).
\end{abstract}

Conclusion: A single HL screening item is useful for quickly estimating $\mathrm{HL}$ and numeracy skills in native Spanish-speaking adults.

Keywords: Health literacy, Numeracy, Spanish-speaking, Validation studies

\section{Background}

Hispanics are one of the fastest-growing minority groups in the United States, as well as a group considered to be at particularly high risk for problems associated with low health literacy $(\mathrm{HL})$ and numeracy [1]. A growing body of literature documents the strong association of limited HL and numeracy with a wide array of poor healthrelated outcomes, knowledge, and behaviors [2]. Among Spanish-speaking adults in the United States specifically, those with limited HL and/or numeracy have shown to have difficulty understanding and acting upon emergency department discharge instructions [3], are less likely to adequately dose pediatric medications correctly [4], are at increased risk of seeking care at emergency departments and urgent care centers in response to their children's asthma exacerbations [5], and are less likely to receive routine mammography [6].

\footnotetext{
* Correspondence: Lorraine.Wallace@osumc.edu

${ }^{3}$ Department of Family Medicine, The Ohio State University, 2231 North High Street, Columbus, $\mathrm{OH} 43210$, USA

Full list of author information is available at the end of the article
}

While valid and reliable HL assessment tools such as the Rapid Estimate of Adult Literacy in Medicine [7], Test of Functional Health Literacy in Adults [8], Health Literacy Skills Instrument [9], Health Literacy Assessment using Talking Touchscreen Technology (Health LiTT) [10], and Health Literacy Management Tool (HeLMS) [11] are available for predominantly research purposes, time constraints often limited their use in busy clinical settings. Recognizing that it is often difficult for clinicians to identify patients at risk of limited HL based the conversation exchange during clinical encounters [12-14], shorter HL assessment tools such as the Short Assessment of Health Literacy (SAHL) [15], Newest Vital Sign (NVS) [16], and Communicative, Functional, Critical Health Literacy scales $[17,18]$ could, potentially, be useful in busy clinical settings to gauge a patient's HL skills. The NVS-which can be administered in less than three minutes $[19,20]$-is perhaps one of the most feasible HL assessment tools for use in routine clinical practice.

C Biomed Central

of

(c) 2015 Singh et al. Open Access This article is distributed under the terms of the Creative Commons Attribution 4.0 International License (http://creativecommons.org/licenses/by/4.0/), which permits unrestricted use, distribution, and reproduction in any medium, provided you give appropriate credit to the original author(s) and the source, provide a link to the Creative Commons license, and indicate if changes were made. The Creative Commons Public Domain Dedication waiver (http://creativecommons.org/publicdomain/zero/1.0/) applies to the data made available in this article, unless otherwise stated. 
Among English-speaking populations, studies have revealed mixed results regarding whether patients' feel comfortable or not disclosing their limited HL to health care providers [21-24]. For instance, in studies were the REALM [21, 23] and TOFHLA [22] were administered, patients with limited HL reported a tremendous amount of shame in sharing their results with their health care providers. However, VanGeest and colleagues [24] found that among those completing the NVS, nearly all patients-regardless of NVS score-reported that screening did not cause them to feel shameful and recommended HL screening in routine clinical practice.

Brief one sentence HL and numeracy screening items have been developed and tested, against various formal HL assessment tools, to quickly assess patients' HL and numeracy skills in busy clinical settings [25-28]. While brief HL and numeracy screening items have shown promise in predicting English-speaking adults' HL and numeracy abilities [25-28], less is known regarding the utility of equivalent Spanish-language HL screening items. For instance, Sarkar and colleagues found established HL screening items to be effective in discriminating between those with adequate versus inadequate/marginal HL, as measured by TOHLHA (administered in both English and Spanish) scores, in samples of both English and Spanish speaking diabetes patients aged $\geq 55$ years in San Francisco, California [29]. Similarly, Cordasco et al. [30] found an established HL screening item ("How confident are you filling out medical forms by yourself?" [25]) and self-reported educational attainment of less than 6 years to be predictive of S-(Spanish)TOFHLA scores among elderly ( $\geq 65$ years of age), monolingual diabetic Spanish speakers residing in Los Angeles, California.

Since Spanish speakers tend to be at greater risk for limited HL and numeracy [1], a need exists to further test the predictive value of $\mathrm{HL}$ and numeracy screening items across various, diverse populations throughout the United States. To our knowledge, just two studies, conducted by Sarkar et al. [29] and Cordasco et al. [30], have explored use of HL screening items in predicting TOFHLA scores among Spanish speakers. While both these studies $[29,30]$ provide evidence as to the usefulness of $\mathrm{HL}$ screening items among Spanish speakers, their study populations were limited to older ( $\geq 55$ years of age) adults with established chronic disease (type 2 diabetes) residing in California. Therefore, to address gap in the literature, the purpose of this study was to evaluate the utility of brief HL and numeracy screening items in predicting NVS and SAHL scores among a sample of Spanish-speaking adults residing in a large, Midwestern city in the United States.

\section{Methods}

\section{Study design and recruitment procedures}

This study employed a cross-sectional design where a convenience sample of subjects completed a structured one-on-one interview, in Spanish, with a trained, bilingual (fluent in both English and Spanish) research assistant (RA). During the summers of 2012 and 2013, a total of 151 native Spanish-speaking adults from two community sites in Columbus, Ohio, United States participated in this study. The first community site was a primary care clinic that provided free of charge medical care to Spanish speaking patients. The second community site was a classroom setting where Spanish speaking adults were offered English as-a-second language instruction. In accordance to the Helsinki Declaration, The Ohio State University Biomedical Institutional Review Board approved all research and informed consent procedures employed in this study.

Depending upon community site visited, a RA approached potential study participants in either the waiting area of the primary care clinic or a small meeting room at the English as-a-second language facility. The RA explained the purpose of the study, informed the participant that his/her responses would be anonymous, and that he/she would receive a $\$ 5$ supermarket gift card for partaking in the study. To be eligible to partake in the study, participants had to be $\geq 18$ years of age and speak Spanish as their first (primary) language. Potential participants who appeared acutely ill, had diminished decision-making capacity, and/or had poor visual acuity were excluded. Both RAs were medical students and made the determination as to whether a participant was well enough to partake in the study. However, just one participant, over the course of both summers, was deemed too acutely ill to partake in the study. At all sites combined, approximately $\approx 86 \%$ of adults approached to partake in the study agreed to do so. The most commonly cited reason for refusing to participate in the study was lack of interest.

\section{Structured interview process and instrumentation}

Those agreeing to participate in the study were taken to a private area (i.e., empty clinical examination or classroom) to complete a 10 to $15 \mathrm{~min}$ one-on-one interview. Upon receiving verbal consent from each participant, the RA began the one-on-one structured interview in Spanish. To begin the interview, the RA administered 5 sociodemographic items (sex, age, formal educational attainment, and self-reported health status) from the 2010 Spanish-language version of the Center for Disease Control and Prevention's Behavioral Risk Factor Surveillance Survey [31].

Second, the RA administered $3 \mathrm{HL}$ and 3 numeracy screening items to each participant. The HL screening items and response options were initially developed and validated in English by Chew and colleagues [25] and then translated into Spanish by Sarkar et al. [29]. As 
shown in Table 1, we used the Spanish version of these HL items and response options, in our study, that were developed by Sarkar et al. [29]. The numeracy screening items and response options developed by Woloshin et al. [32] and Fagerlin et al. [33] were translated from English to Spanish for our study. Specifically, the second author and along with a native Spanish speaker collectively translated the numeracy items and corresponding response options into Spanish.

Third, the RA administered the 18-item SAHL [15] to each participant. The SAHL is a validated HL tool assessing Spanish-speaking adults' ability to read and comprehend basic medical terms. Individual SAHL items are presented to the interviewee in flashcard format. The "stem" is printed at the top of the card in boldface while two associated words-"key" and "distractor"-appear at the bottom of the card. The participant is asked to identify which word is associated with the "stem" word. As an example, one card presented had the stem word "pregnancy" [embarazo] with the two associated words "birth" [parto] and "childhood" [niñez]. Each participant then had to distinguish whether "birth" or "childhood" was more closely related to the stem word "pregnancy." Per established SAHL scoring guidelines, those scoring $\leq 14$ were categorized as having inadequate HL.

To conclude the interview, the RA administered the NVS to each participant. The, NVS, consisting of 6 questions, includes a combination of reading comprehension and manipulation of numerical data to interpret content presented within an ice cream container nutrition label [16]. The valid and reliable Spanish language version of the NVS, including questions and the accompanying ice cream nutrition label, were presented to participants. As an example, one NVS question asks, "If you eat all the ice cream in the container, how many calories will you have consumed,?" ["Si usted se come todo el helado en el envase, ¿cuántas calorías habrá consumido?”] requiring participants to locate nutritional information on the label and apply basic math skills. Based on established NVS scoring thresholds, participants were classified as having limited $(\mathrm{NVS}=0-1)$, marginal $(\mathrm{NVS}=2-3)$, or adequate (NVS = 4-6) HL/numeracy skills. The NVS has been validated in previous studies [34-36].

\section{Statistical analysis}

Data were analyzed using the Statistical Package for the Social Sciences (SPSS+ 20.0, Chicago, IL). A priori, statistical significance was set at $p<0.05$. Descriptive statistics (means, standard deviations, frequencies, percentages) were conducted to depict sociodemographic and HL and numeracy characteristics of the study sample.

Spearman's rank correlation coefficient was used to estimate the relationship between NVS and SAHL scores. Next, using both NVS and SAHL scores as reference standards, we computed area under the ROC (AUROC) curves for individual $\mathrm{HL}$ and numeracy screening items.

Table 1 English to spanish language translation of established health literacy and numeracy screening items and response options

English Language
How often do you have problems learning about your medical condition
because of difficulty understanding written information? ${ }^{17}$
Always - Often - Occasionally - Sometimes - Never
How confident are you filling out medical forms by yourself? ${ }^{17}$
Extremely - Quite a bit - Somewhat - A little bit - Not at all
How often do you have someone help you read hospital materials? ${ }^{17}$

Always - Often - Occasionally - Sometimes - Never

In general, how easy or hard do you find it to understand medical statistics? ${ }^{25}$

Very easy - Easy - Hard - Very hard

How much do you agree or disagree with the following statement? In general, I feel uncomfortable with health information that has a lot of numbers and statistics. ${ }^{26}$

Strongly agree - Somewhat agree - Somewhat disagree - Strongly disagree

How much do you agree or disagree with the following statement? In general, I depend on numbers and statistics to help me make decisions about my health. ${ }^{26}$

Strongly agree - Somewhat agree - Somewhat disagree - Strongly disagree Spanish Language

¿Qué tan seguido tiene problemas aprendiendo sobre su condición médica porque es difícil entender información escrita?

Siempre - Con mucha frecuencia - A veces - De vez en cuando - Nunca

¿Qué tan seguro(a) se siente al llenar formas usted solo(a)?

Completamente seguro(a) - Bastante seguro(a) - Algo seguro(a) - Un poco seguro(a) - Para nada

¿Qué tan seguido tiene usted, un familiar, un amigo, un empleado del hospital o la clínica u otra persona que le ayude a leer materiales del hospital?

Siempre - Con mucha frecuencia - A veces - De vez en cuando - Nunca

En general, ¿qué tan fácil o difícil es para usted entender estadísticas sobre temas médicos?

Muy fácil - Fácil - Difícil - Muy difícil

¿Cuánto está usted de acuerdo o en desacuerdo con la siguiente afirmación? En general, no encuentro clara la información sobre salud cuando tiene muchos números y estadísticas.

Totalmente de acuerdo - Algo de acuerdo - Algo en desacuerdo Totalmente en desacuerdo

¿Cuánto está usted de acuerdo o en desacuerdo con la siguiente afirmación? En general, me baso en números y estadísticas para tomar decisiones acerca del mi salud.

Totalmente de acuerdo - Algo de acuerdo - Algo en desacuerdo Totalmente en desacuerdo 
Table 2 Sociodemographic characteristics of study participants $(n=151)$

\begin{tabular}{lll}
\hline $\begin{array}{l}\text { Sociodemographic } \\
\text { Characteristics }\end{array}$ & $\begin{array}{l}\text { Mean } \pm \text { Standard } \\
\text { Deviation or Frequency }\end{array}$ & Percent (\%) \\
\hline Age in Years & $36.8 \pm 11.0$ & - \\
Sex & & \\
$\quad$ Male & 69 & 45.7 \\
$\quad$ Female & 82 & 54.3 \\
Educational Attainment & & \\
$\quad$ < High School & 124 & 82.2 \\
$\quad$ Z High School & 27 & 17.8 \\
Self-rated Health Status & & \\
$\quad$ Poor/Fair & 26 & 17.2 \\
$\quad$ Good & 48 & 31.8 \\
$\quad$ Very Good/Excellent & 77 & 51.0 \\
\hline
\end{tabular}

AUROCs allowed us to compare the predictive ability of individual screening questions in estimating limited/ marginal NVS scores or inadequate SAHL scores. An ideal question has an AUROC of 1.0, while an AUROC $\leq 0.5$ indicates a screening item that provides no useful information.

\section{Results}

The overall sociodemographic characteristics of our sample are described in Table 2. Distribution of SAHL and NVS scores is presented in Figs. 1 and 2, respectively. Overall, participants averaged $15.7 \pm 2.8$ correct responses on the SAHL with $22.4 \%$ classified as having inadequate HL (SAHL $\leq 14)$. Participants averaged $1.70 \pm 1.54$ correct NVS responses with the majority (60.5\%) classified as having limited numeracy (NVS score $=0$ or 1 ). Overall, NVS and SAHL scores were weakly correlated with one another $(r h o=0.39 ; P<0.01)$ [37].
AUROCs for individual HL and numeracy screening items in identifying participants with limited/marginal NVS scores and/or inadequate SAHL scores are shown in Table 3. Across both reference standards, the HL screening item, "How confident are you filling out medical forms by yourself?", performed best in detecting limited NVS scores (AUROC $=0.75 ; 95 \% C I=0.65-0.84$ ), limited/marginal NVS scores (AUROC $=0.66$; $95 \%$ confidence interval $[\mathrm{CI}]=0.57-0.75$ ), and inadequate SAHL scores (AUROC $=0.69 ; 95 \% C I=0.58-0.79$ ). The numeracy screening item, "In general, how easy or hard do you find it to understand medical statistics,?" was best in detecting limited NVS scores (AUROC $=0.71 ; 95 \% C I=$ $0.60-0.83$ ) but only moderately well in detecting limited/ marginal NVS scores (AUROC $=0.61 ; 95 \% C I=0.51-$ $0.70)$ and inadequate SAHL scores (AUROC $=0.59 ; 95 \%$ $C I=0.48-0.70)$. For the remaining $\mathrm{HL}$ and numeracy screening items, AUROC scores ranged from 0.27 ("How often do you have problems learning about your medical condition because of difficulty understanding written information?", in detecting limited numeracy) to 0.50 ("How often do you have someone help you read hospital materials", in detecting inadequate $\mathrm{HL}$ ).

\section{Discussion}

This study examined utility of brief HL and numeracy screening items in predicting NVS and SAHL scores among a sample of Spanish-speaking adults residing in a large, Midwestern city in the United States. Overall, participants in this study had lower numeracy as compared to general HL skills as measured by the NVS and SAHL, respectfully. The most important finding from our study was that two screening items ("How confident are you filling out forms by yourself?" and "In general, how easy or hard do you find it to understand medical statistics?") were both strong predictors of overall NVS and SAHL scores.

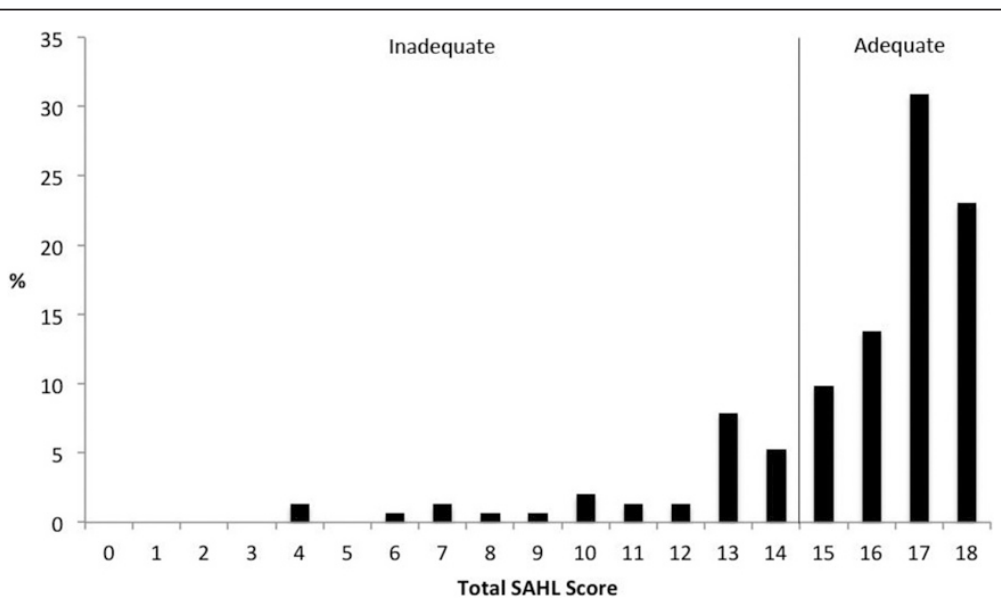

Fig. 1 Distribution of participants' Short Assessment of Health Literacy (SAHL) scores across established scoring thresholds 


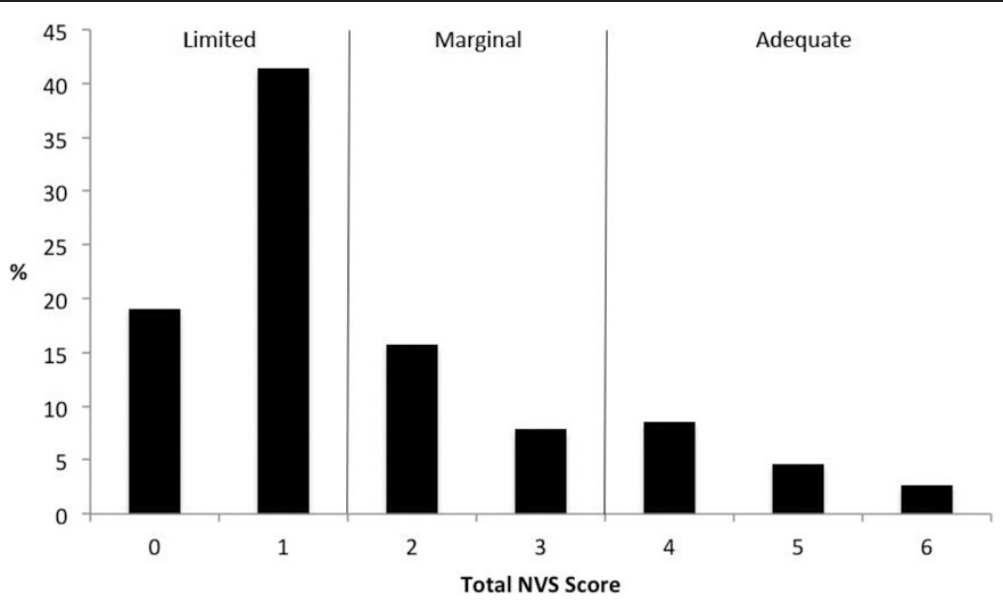

Fig. 2 Distribution of Participants' Newest Vital Sign (NVS) scores across established scoring thresholds

Our findings extend the results of prior studies in which the "confident with forms" item was the best predictor of identifying patients at risk of inadequate $\mathrm{HL}$ [25-30, 38]. In contrast to Sarkar et al. [29], who found that all of Chew's [25] screening items performed well in Spanish speakers, the "confident with forms" item was a much better predictor of NVS and SAHL scores in our study population. However, our results mirror those of Cordasco et al. [30], who found the "confident with forms" item to be the best predictor of inadequate TOFHLA scores in their population of monolingual Spanish speakers in Los Angeles, California. The combined findings of our study and Sarkar's, and Cordasco's studies provide strong evidence for the benefit of using a single Spanish HL screening item to estimate a participants' HL and/or numeracy skills.

In comparison to earlier studies in English-speaking populations [25-30, 38], Chew's [25] brief HL screening items had lower AUROCs among our Spanish-speaking population. In part, this may be due to participants' interpretation of the items as referring to forms and materials written in English, not Spanish. Thus, participant responses may reflect difficulties in reading and interpreting materials in English, rather than their ability to read and respond to materials written in their native language. Future work, could perhaps, specify that written material and forms refer to those in the participant's native (Spanish) language.

Unlike Sarkar et al. [29] and Cordasco et al. [30] who used the TOFHLA as their reference standard, we used the NVS and SAHL as reference standards. It is interesting to note that while nearly $60.5 \%$ of our Spanish speaking population had limited HL (using SAHL scores as the reference) and $84.2 \%$ had limited/marginal based on NVS scores, only $22.4 \%$ were categorized as having inadequate HL based on SAHL scores. Our findings are similar to those reported by Ramirez-Zohfeld and colleagues [39] in that categorization of participants into levels of literacy is likely to vary across HL assessment tool employed.

The overall proportion of low NVS scores could reflect a combination of both low numeracy-related skills and/

Table 3 Area Under the Receiving Operating Curves (AUROC) for Health Literacy (HL) and Numeracy Screening Items Using Newest Vital Sign (NVS) and Short Assessment of Health Literacy (SAHL) standards

\begin{tabular}{|c|c|c|c|}
\hline Health Literacy and Numeracy Screening Item & $\begin{array}{l}\text { Limited } \\
\text { Numeracy (NVS) }\end{array}$ & $\begin{array}{l}\text { Limited/Marginal } \\
\text { Numeracy (NVS) }\end{array}$ & $\begin{array}{l}\text { Inadequate Health } \\
\text { Literacy (SAHL) }\end{array}$ \\
\hline $\begin{array}{l}\text { How often do you have problems learning about your medical condition } \\
\text { because of difficulty understanding written information? }\end{array}$ & $0.27(0.16-0.37)$ & $0.46(0.37-0.56)$ & $0.47(0.36-0.56)$ \\
\hline How confident are you filling out medical forms by yourself? & $0.75(0.65-0.84)$ & $0.66(0.57-0.75)$ & $0.69(0.58-0.79)$ \\
\hline How often do you have someone help you read hospital materials? & $0.42(0.27-0.57)$ & $0.47(0.37-0.56)$ & $0.50(0.40-0.60)$ \\
\hline In general, how easy or hard do you find it to understand medical statistics? & $0.71(0.60-0.83)$ & $0.61(0.51-0.70)$ & $0.59(0.48-0.70)$ \\
\hline $\begin{array}{l}\text { How much do you agree or disagree with the following statement? In general, I feel } \\
\text { uncomfortable with health information that has a lot of numbers and statistics. }\end{array}$ & $0.44(0.32-0.57)$ & $0.49(0.40-0.59)$ & $0.47(0.36-0.59)$ \\
\hline $\begin{array}{l}\text { How much do you agree or disagree with the following statement? In general, } \\
\text { I depend on numbers and statistics to help me make decisions about my health. }\end{array}$ & $0.44(0.32-0.57)$ & $0.49(0.39-0.58)$ & $0.40(0.30-0.50)$ \\
\hline
\end{tabular}

Numeracy and HL levels based on NVS scores (limited $=0$ or 1 ; marginal $=2$ or 3 ) and SAHL scores (inadequate $\leq 14$ ). AUROCs calculated with $95 \%$ confidence intervals 
or unfamiliarity with nutrition labels among Spanish speakers. Many of the participants tested were unsure of how to read and interpret the ice cream nutrition label provided. Thus, NVS scores may not provide good discrimination of numeracy skill levels among Spanish speakers. Future investigations should examine and compare the validity of different HL/numeracy assessment tools in Spanishspeaking and other diverse populations. Additionally, research is needed to explore whether gender differences exist in self-report of health literacy. For example, among a large sample of Taiwanese adults, Lee et al. [40] found that women's responses to HL screening items reflected their actual HL scores (as assessed by the Mandarin Health Literacy Scale), whereas men tended to over-report their actual HL skills. Further study is warranted to see if these findings emerge in Spanish-speaking populations as well.

Our study findings should be considered in light of several potential limitations. First, participants in this study were sampled in a single Midwestern city in the United States drawn largely from free clinics where patients are often uninsured and/or have modest incomes. As a result, our findings may not be representative of other more geographically and/or socioeconomically diverse settings. Second, we were unable to stratify participants into more detailed categories of educational attainment due to differences in schooling and descriptions used to describe the educational systems in Spanish-speaking countries. Third, our findings reflect the criterion validity of the $\mathrm{HL}$ and numeracy screening items against both the NVS and SAHL. Fourth, as with all observational studies that rely on self-reports, response bias remains a possibility.

\section{Conclusions}

Brief one sentence $\mathrm{HL}$ and numeracy screening items have utility in screening for limited HL and numeracy in Spanish-speaking adults. The "confident with forms" item discriminates well amongst Spanish-speaking adults with varying $\mathrm{HL}$ and numeracy skills. This single question can be easily administered in a variety of clinical settings and eliminate the need for more formal and lengthy HL and/or numeracy assessments.

\section{Competing interests}

The authors declare that they have no competing interests.

\section{Authors' contributions}

RS: participated in the development and implementation of methods and manuscript preparation, LC: participated in the development and implementation of methods and manuscript preparation, and LW: conceived of the study design, developed the methods, performed the statistical analysis, drafted the original manuscript, and drafted the revised manuscript and responses to peer reviewers. All authors read and approved the final manuscript.

\section{Author details}

${ }^{1}$ The Ohio State University, Wexner College of Medicine, Columbus, $\mathrm{OH}$ 43210, USA. ${ }^{2}$ University of Kentucky, Lexington, KY 40506, USA. ${ }^{3}$ Department of Family Medicine, The Ohio State University, 2231 North High Street, Columbus, OH 43210, USA.
Received: 21 February 2015 Accepted: 7 September 2015

Published online: 14 September 2015

\section{References}

1. Kutner M, Greenberg E, Jin Y, Paulsen, C. The health literacy of America's Adults: results from the 2003 National Assessment of Adult Literacy: National Center for Education Statistics. Washington, DC: US Department of Education; 2006.

2. Dewalt DA, Berkman ND, Sheridan S, Lohr KN, Pignone MP. Literacy and health outcomes: A systematic review of the literature. J Gen Intern Med. 2004;19:1228-39.

3. Smith PC, Brice JH, Lee J. The relationship between functional health literacy and adherence to emergency department discharge instructions among Spanish-speaking patients. J Natl Med Assoc. 2012;104:521-7.

4. Samuels-Kalow ME, Stack AM, Porter SC. Parental language and dosing errors after discharge from the pediatric emergency department. Pediatr Emerg Care. 2013;29:982-7.

5. Rosas-Salazar C, Ramratnam SK, Brehm JM, Han YY, Acosta-Pérez E, Alvarez M, et al. Parental numeracy and asthma exacerbations in Puerto Rican children. Chest. 2013;144:92-8.

6. Pagán JA, Brown CJ, Asch DA, Armstrong K, Bastida E, Guerra C. Health literacy and breast cancer screening among Mexican American women in South Texas. J Cancer Educ. 2012;27:132-7.

7. Davis TC, Long SW, Jackson RH, Mayeaux EJ, George RB, Murphy PW, et al. Rapid estimate of adult literacy in medicine: a shortened screening instrument. Fam Med. 1993;25:391-5.

8. Parker RM, Baker DW, Williams MV, Nurss JR. The test of functional health literacy in adults: a new instrument for measuring patients' literacy skills. J Gen Intern Med. 1995;10:537-41.

9. Bann CM, McCormack LA, Berkman ND, Squiers LB. The health literacy skills instrument: a 10-item short form. J Health Commun. 2012;17 Suppl 3:191-202.

10. Hahn EA, Choi SW, Griffith JW, Yost KJ, Baker DW. Health literacy assessment using talking touchscreen technology (Health LiTT): A new item response theory-based measure of health literacy. J Health Commun. 2011;16 Suppl 3:150-62.

11. Jordan JE, Buchbinder R, Briggs, AM, Elsworth GR, Busija L, Batterham R, et al. The Health Literacy Management Scale (HeLMS): A measure of an individual's capacity to seek, understand and use health information within the healthcare setting. Patient Educ Couns. 2013;91:228-35.

12. Bass PF, Wilson JF, Griffith CH, Barnett DR. Residents' ability to identify patients with poor literacy skills. Acad Med. 2002;77:1039-41.

13. Lindau ST, Tomori C, Lyons T, Langseth L, Bennett CL, Garcia P. The association of health literacy with cervical cancer prevention knowledge and health behaviors in a multiethnic cohort of women. Am J Obstet Gynecol. 2002;186:938-43.

14. Rogers ES, Wallace LS, Weiss BD. Misperceptions of medical understanding in low-literacy patients: implications for cancer prevention. Cancer Control. 2006;13:225-9

15. Lee SY, Stucky BD, Lee JY, Rozier RG, Bender DE. Short assessment of health literacy-Spanish and English: a comparable test of health literacy for Spanish and English speakers. Health Serv Res. 2010;45:1105-20.

16. Weiss BD, Mays MZ, Martz W, Castro KM, DeWalt DA, Pignone MP, et al. Quick assessment of literacy in primary care: the newest vital sign. Ann Fam Med. 2005;3:514-22.

17. Ishikawa N, Nomura K, Sato M, Yano E. Developing a measure of communicative and critical health literacy: a pilot study of Japanese office workers. Health Promot Int. 2008;23:269-71.

18. Ishikawa N, Takeuchi T, Yano E. Measuring functional, communicative, and critical health literacy among diabetic patients. Diabetes Care. 2008;31:874-9.

19. Johnson $K$, Weiss BD. How long does it take to assess literacy skills in clinical practice? J Am Board Fam Med. 2008;21:211-4.

20. WelchVL, VanGeest JB, Caskey R. Time, costs, and clinical utilization of screening for health literacy in primary care: A case study using the Newest Vital Sign (NVS) instrument. J Am Board Fam Med. 2011;24:281-9.

21. Baker DW, Parker RM, Williams MV, Pitkin K, Parikh NS, Coates W, et al. The health care experience of patients with low literacy. Arch Fam Med. 1996;5:329-34

22. Parikh NS, Parker RM, Nurss JR, Baker DW, Williams MV. Shame and health literacy: the unspoken connection. Patient Educ Couns. 1996;27:33-9.

23. Wolf MS, Williams MV, Parker RM, Parikh NS, Nowlan AW, Baker DW. Patients' shame and attitudes toward discussing the results of literacy screening. J Health Comm. 2007;12:721-32. 
24. VanGeest JB, Welch VL, Weiner SJ. Patients' perceptions of screening for healthliteracy: reactions to the Newest Vital Sign. J Health Comm. 2010;15:402-12.

25. Chew LD, Bradley KA, Boyko EJ. Brief questions to identify patients with inadequate health literacy. Fam Med. 2004;36:588-94.

26. Wallace LS, Rogers ES, Roskos SE, Holiday DB, Weiss BD. Screening items to identify patients with limited health literacy skills. J Gen Intern Med. 2006;21:874-7.

27. Al Sayah F, Majumdar SR, Egede LE, Johnson JA. Measurement properties and comparative performance of health literacy screening questions in a predominantly low income African American population with diabetes. Patient Educ Couns. 2014;97:88-95.

28. Schwartz KL, Bartoces M, Campbell-Voytal K, West P, Monsur J, Sartor A, et al. Estimating health literacy in family medicine clinics in metropolitan Detroit: a MetroNet study. J Am Board Fam Med. 2013;26:566-70.

29. Sarkar U, Schillinger D, López A, Sudore R. Validation of self-reported health literacy questions among diverse English and Spanish-speaking populations. J Gen Intern Med. 2011;26:265-71.

30. Cordasco KM, Homeier DC, Franco I, Wang PC, Sarkisian CA. Health literacy screening of geriatric monolingual Spanish-speaking patients using singleitem literacy screening questions and education. Health Educ J. 2012;71:597-605

31. Behavioral Risk Factor Surveillance Survey_2010 Spanish Questionnaire. http://www.cdc.gov/brfss/annual_data/pdf-ques/q2010span.pdf Accessed July 21, 2014.

32. Woloshin S, Schwartz LM, Welch HG. Patients and medical statistics. Interest, confidence, and ability. J Gen Intern Med. 2005;20:996-1000.

33. Fagerlin A, Zikmund-Fisher BJ, Ubel PA, Jankovic A, Derry HA, Smith DM. Measuring numeracy without a math test: development of the Subjective Numeracy Scale. Med Decis Making. 2007;27:672-80.

34. Osborn CY, Weiss BD, Davis TC, Skripkauskas S, Rodrigue C, Bass PF, et al. Measuring adult literacy in health care: performance of the newest vital sign. Am J Health Behav. 2007:31 Suppl 1:S36-46.

35. Patel PJ, Joel S, Rovena G, Pedireddy S, Saad S, Rachmale R, et al. Testing the utility of the newest vital sign (NVS) health literacy assessment tool in older African-American patients. Patient Educ Couns. 2011:85:505-7.

36. Shah LC, West P, Bremmeyr K, Savoy-Moore RT. Health literacy instrument in family medicine: the "Newest Vital Sign" ease of use and correlates. J Am Board Fam Med. 2010;23:195-203.

37. Stats Tudor. Spearman's correlation. http://www.statstutor.ac.uk/resources/ uploaded/spearmans.pdf Accessed July 30, 2015

38. Stagliano V, Wallace LS. Brief health literacy screening items predict Newest Vital Sign scores. J Am Board Fam Med. 2013;26:558-65.

39. Ramirez-Zohfeld V, Rademaker AW, Dolan NC, Ferreira MR, Eder MM, Liu D, et al. Comparing the performance of the S-TOFHLA and NVS among and between English and Spanish speakers. J Health Comm. 2015;6:1-7.

40. Lee SY, Tsai TI, Tsai YW. Accuracy in self-reported health literacy screening: A difference between men and women in Taiwan. BMJ Open. 2013;3(11):e002928.

\section{Submit your next manuscript to BioMed Central and take full advantage of:}

- Convenient online submission

- Thorough peer review

- No space constraints or color figure charges

- Immediate publication on acceptance

- Inclusion in PubMed, CAS, Scopus and Google Scholar

- Research which is freely available for redistribution 